\title{
Miracles of Book and Body: Buddhist Textual Culture and Medieval Japan, by Charlotte Eu- banks
}

Berkeley and Los Angeles: University of California Press, 20I I |xviii + 269 pages | ISBN: 978-0-520-2656I-5 (hardback) $\$ 55.00$

Charlotte Eubanks's elegantly written study of mate-

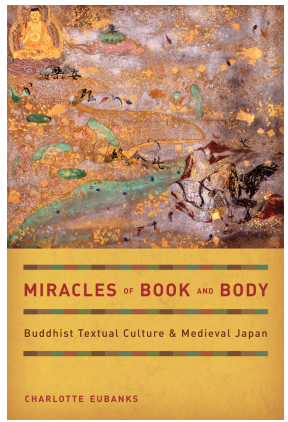
riality and textuality is an inquiry into Buddhist textual culture and religious practice, primarily of Mahāyāna Buddhism in medieval Japan. More specifically, she offers an analysis of setsuwa or the explanatory notes that often accompanied sermons to illustrate doctrine. The setsuwa typically employed popular stories about the Buddha and his followers as a method of expanding on the dharma. These were compiled into various literary collections between the ninth and thirteen centuries in Japan and thus they span the period when Buddhism expanded beyond the court into every level of Japanese society. The first significant Buddhist collection ( $A$ Wondrous Record of Immediate Karmic Retribution) was put together in the 820 and the final collection (Collection of Sand and Pebbles) was completed in the 1280 . These collections correspond to the Heian (794-I I 85 ) and Kamakura (I I 8 5-I 333 ) periods. In this era, which for convenience she calls "medieval," the advent of Buddhism coincided with the introduction of a written script from China, and produced an aesthetics that was distinctively Buddhist. While much of the material in the setsuwa had its origin in oral narrative, the Japanese genre of these explanatory tales was influenced by both Indian and Chinese narrative forms. Of special note were the Indian "karmic biography" and birth tales, and Chinese miracle stories.

These setsuwa collections emerged out of centres of aristocratic culture in or near the imperial city of Heiankyo (or modern day Kyoto) and, although their main characters came from a wide variety of social classes and status groups, these narratives reflect the habitus of the nobility and hence the premium that their life style placed on personal cultivation and cultural sophistication. However these narratives also recognized the emotional volatility of amorous relationships and the violence that inescapably attends politics. The collections were composed by three authorial categories: the laity, 
clerics writing for professional purposes, and individuals either writing for themselves or for a specific individual. The latter texts are deeply poetic and personal with ample use of allusion and metaphor.

Concentrating on nine collections of setsuwa that serve as the basis of her study, she examines them alongside the canonical sutra texts, demonstrating how these popular stories unite text and audience into a "textual community" in which setsuwa and sutras intersect. Her account of the centrality of this literature to Mahāyāna Buddhism depends to some degree on Gregory Schopen's Figments and Fragments of Mahāyanna Buddhism in India: More Collected Papers (Honolulu: University of Hawai'i Press, 2005) in which he coined the phrase "the cult of the book." Eubanks comments that "the Mahāyāna distinguished itself by establishing cultic centers organized not around stupas, but rather around written sutra texts that were recited, worshipped, honored, and circumambulated" (2I).

Eubanks sets herself three questions for which this publication seeks to provide answers. The first question is about ontology - where does text exist? The second question is sociological- how can we understand text not (only) as a material "thing" but (also) as material "event"? The final question is historical—what do Buddhist books look like? Who created them where, when and how? We might suggest that a single answer to these valuable questions is that Buddhist scriptures came alive through embodied performances that created communities that became the vehicles for the maintenance and transmission of the dharma.

To open this review, we might take the three nouns that form the title of her book. First, and following the work of Caroline Walker Bynum on miracles and the theology of redemption in medieval Europe (Fragmentation and Redemption: Essays on Gender and the Human Body in Medieval Religion [New York: Zone Books, I 992]), Eubanks observes that, while miracles are unexpected and unpredictable, there are methods-prayer, fasting, selfmutilation, and sleep deprivation — by which they may be courted. Similar religious methodologies were embraced in Japan, where wakefulness, prayer, pilgrimage, and training of the memory were practices by which the devotee might receive a miraculous sign. Secondly, she offers a close study of the setsuwa as literature in which she excavates "some of the symbols and structures through which sutras build themselves into narratives of meaning, paying special attention to the metacommentary that sutras offer about how they should be read and about the place of reading vis-à-vis other methods of 
textual engagement, such as recitation and circumambulation" (13). Thirdly this study is a sustained analysis of how the human body is connected with the body of the text. Eubanks proposes that the body and sutras are comparable, namely they are exemplary sites where the core themes of Buddhist teaching on suffering and impermanence can be strikingly encountered. We need here to comment briefly on the idea of body. The human body is a special type of container for Buddha's teaching and is referred to as the "dharma vessel." More precisely, the human body is "the embodied sense organ of the mind" ( 56$)$.

There are two important themes that are established in the Introduction and Chapter I on "The Ontology of Sutras." The first theme is the relationship between the textual and the oral, and between the text and the work. The setsuwa and sutras were written on scrolls of various sorts but they were also to be read and recited, and hence they depended on performance. Literature as a result exists at two interconnected places, namely on the printed page and in the minds of a social community of readers and writers. In the field of textual studies, it is consequently important to make a distinction between the text and the work. The latter is an assemblage of pieces of literature that can be expressed in the various forms (in folio, quarto, in vellum, or in a great variety of editions) but it cannot be reduced to any single one of these expressions. Furthermore the linguistic text can be housed in any number of material forms of physical containers. The linguistic text and the physical container is the "material text," and this text is available to the human senses. In reference to Buddhist literature, the sutra as a linguistic text (a string of words and line breaks) is an abstraction that survives by situating itself in a container such as popular memory or on an external surface of leaves or paper, but these are perishable. However the sutra as work continues to live as an abiding teaching in the dharma. Writing and memory were simply two techniques for storing a text. As places for storage, both were subject to damage, decay, and erasure. The work itself by contrast was eternal and sacred.

There are in fact three classical means of storage. These are the stupa-ascontainer, the scroll-as-container, and the mind-as-container. This discussion of how the dharma is to be held and transmitted brings us to what I regard as the second dominant theme of Eubanks's study, namely the vulnerability of things, texts, and bodies. Buddha and his disciples were constantly aware that the dharma might be lost, destroyed, or corrupted. How could its trans- 
mission over time be guaranteed against both external and internal threats? Stupas can be destroyed, scrolls can be corrupted, and memories can fade. Memory is unreliable and the body is frail and subject to decomposition. Indeed contemplation of a rotting human corpse is an established component of Buddhist monastic training. The Buddhist aspirant would visit a charnel house in order to gaze upon the full horror of decomposition and degradation. Various setsuwa describe how a lay person, suddenly confronted by a dead and decaying body is moved to follow the Buddhist path.

One response to this dilemma of vulnerability was to emphasise the importance of discipline and training in the memorization and recitation of texts. Eubank approaches this issue through a discussion of the idea of accepting and holding onto the sutras. The idea of holding onto the teaching has two components- the one who accepts and holds, and that which is accepted and held. While monks and laity may aspire to perfect memory, the power of total recall belongs only to buddhas and the most advanced bodhisattvas. The Flower Ornament Sutra asserts that the core quality of buddhas is that they are able to accept and hold on to all Buddha dharmas. For bodhisattvas the cultivation of free and unhindered access to the dharma comes only after endless lifetimes of discipline in which they start with text and conclude with the work or dharma. The devotee Sudhana was able to move from cataloguing individual sermons to accessing the complete dharma library. Memorizing the teaching had thus transformed him into a storehouse of the dharma.

The Mahāyāna vocabulary often had an erotic dimension in that the sutras live within the body of believers who are dharma vessels in providing shelter and protection. In return the sutras can have miraculous effects in giving relief from illness and promoting longevity. There is an exchange relationship or symbiosis between the gift of the dharma and the activities of humans. Human bodies can break down into textual fragments and textual fragments can become embodied in humans. In this symbiotic relationship, the humans become womb-like containers into which the seed of the teaching is inserted. From these metaphors, we can learn that Mahāyāna Buddhism understood paper (or other writing surfaces such as leaves or silk) and the human body as simply material locations for the inscription of sacred texts. The setsuwa were self-reflexive in their approach to somaticity, materiality, and ontology in which the text-flesh relationship was paramount within the narratives. While these erotic metaphors were common, the setsuwa texts 
were also conceived as a type of food or medicine which had to be ingested. The purpose of the text was to nourish and sustain mind and body, bringing about a religious awakening and growth.

Charlotte Eubanks's Miracles of Book and Body is a major contribution to the study of Japanese setsuwa as literature and, bringing her literary-critical skills to bear on these texts, she has fully excavated the wealth of narrative techniques that were skilfully deployed to hold an audience and thereby to transmit the work as dharma. However, this captivating study can also be understood more comprehensively as a contribution to the contemporary interest in the human body ("the turn to the body"), performance, popular culture, and material cultures. Contemporary scholarship in both anthropology and sociology has been critical of the narrow focus in traditional scholarship on religious belief and the corresponding neglect of practice, performance, and ritual. This conventional focus on religion as belief has been attributed to the legacy of Protestantism on religious studies. Eubanks, drawing attention to the performance of setsuwa in the context of Buddhist gatherings to hear sermons, recognises the historical value of Notes on One Hundred Sessions of Sermons, which tells of the network of clerics around the early i Ioos who were identified as talented preachers. These men could be engaged to provide sermons at Buddhist ceremonies that might involve the dedication of a sutra. These narratives give us an insight into the liturgical performance of the ceremonies, the organization of such meetings, the role of local patrons of Buddhist sites and services, and the norms that emerged to determine the order of events. Beginning in the late twelfth century, there were attempts to standardise these norms, which had evolved for the practice of sermons, in order to define their protocols, etiquette, and sequencing. These Notes offer an important insight into actual performance and practice.

Miracles of Book and Body begins with the account of medieval Buddhism with the story of Myoe (I I73-I 232) a monk who decided that a shaved head was no longer sufficient evidence of a person's devotion or true intentions. Seizing a knife, he sawed off his right ear, splattering blood over the ritual implements before him. What was the logic of this pious act? This removal of an ear dramatically defined the physical correlation between text and body. By removing an ear rather than an eye, a hand or a nose, he was still able to see, hold, and hear the sutras. Eubanks returns to this story towards the conclusion of her book to demonstrate the constitutive importance of the text-flesh continuum in Buddhism. Chanting, copying, memorizing, and preaching are religious activities that are aspects of this continuum. The voice that is 
necessary for chanting and the hand that is necessary for copying the scriptures have profound significance; they contain "the presence and the body of the Buddha” (I72). In these devotional performances, miracles, books, and bodies finally come together in a shared ontology.

Bryan S. Turner

The Graduate Center

The City University of New York 